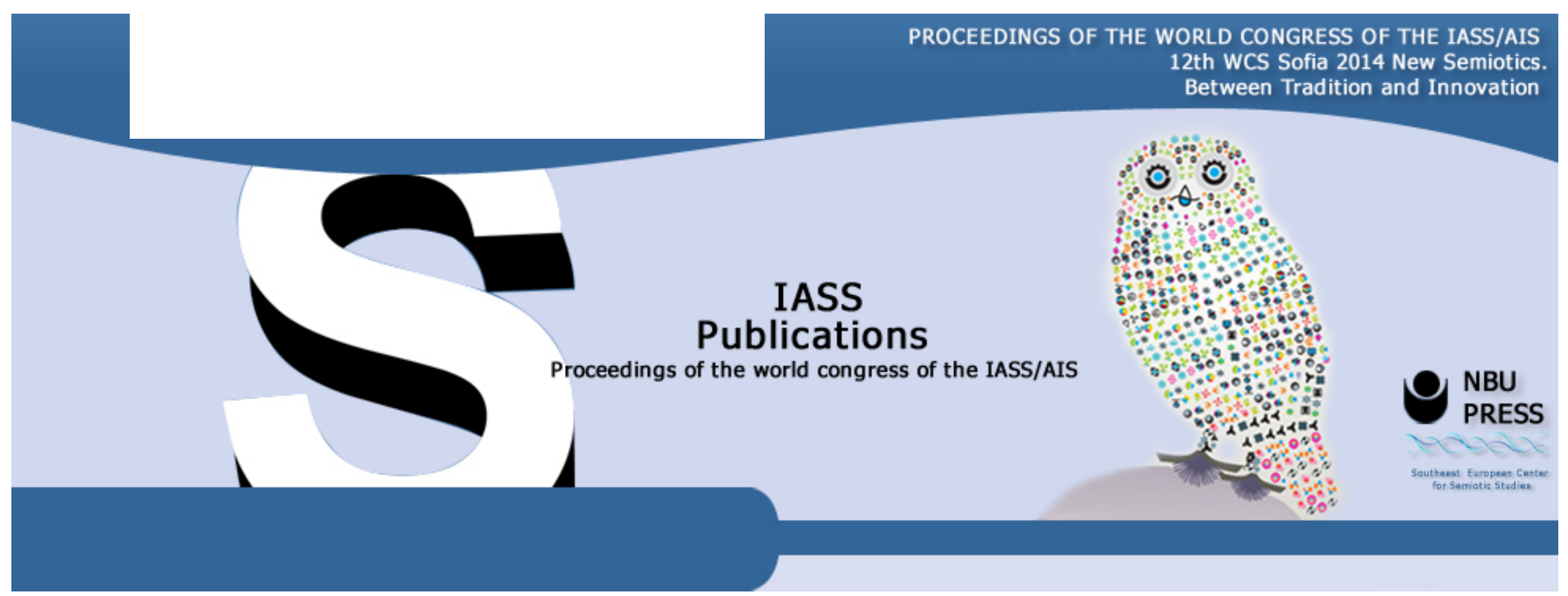

\title{
RETHINKING THE INTERSECTION BETWEEN SOCIAL NETWORKS, URBAN TERRITORIES AND EVERYDAY LIFE PRACTICES. A CRITICAL APPROACH TO THE SPREADING OF HASHTAGS IN URBAN STORYTELLING.
}

Paolo Peverini

Libera Università Internazionale degli Studi Sociali Guido Carli, Rome, Italy

ppeverini@luiss.it

Abstract

In recent years the centrality of a common sense emerged with increasing strength in the social media scenario: the practice of sharing experiences, practices and rituals is fostered by competition among the manifold networks that enliven a communications ecosystem more and more based on everyday life storytelling. 
The aim of this article is to contribute to sociosemiotic recognition of several particularly widespread aspects of the renegotiation of urban everyday life fostered by the pervasive concept of media overexposure. In particular, the article, at the intersection of three axes - social networks, urban territories and everyday life practices - concentrates on the spread of hashtags, seemingly obvious and "transparent" signs that contribute to blurring the borders that separate everyday life in urban territories from the conversations about it. In the social network scenario Instagram is an exemplary case worth investigating, since its growing popularity holds consequences in the representation of urban territories.

\section{Social networks, everyday life practices and urban spaces}

From the standpoint of sociosemiotic research, analysing the complex transformations that affect the combination of city/communication in the context of the forms of an increasingly advanced and pervasive convergence of media involves first of all recognizing that the meaning of places cannot be separated from the presence of linguistic phenomena or the complex mechanisms that correlate numerous forms and substances of expression and content. Indeed, from a preliminary standpoint we must observe that any given city emerges as a semiotic "object" that is undeniably plural and polysemic, characterized by the stratification of meaning that calls for patient analysis, discouraging any attempt at immediate "interpretation".[1]

As Isabella Pezzini has noted in this regard, the semiotic study of a metropolis, in particular, can only

proceed by disaggregation, not only of individual objects - monument, shop, warehouse - but above all based on the properties they share on a given level. Therefore, this would involve identifying levels of interpretation or, in short, isotopies: the same ones that intuitively circulate in social discourses about the city, and where value systems - aesthetic (the beautiful and the ugly), political (social and moral "health") and rational (functionality, economics, etc.) - implicitly intersect, and in which what is always emphasized is a sort of mythology of the relationship between individual and society that the city materializes, often dysphorically (Pezzini 2004: 263).

The processes of signification that characterize the spaces of metropolitan living are founded on complex translation mechanisms (and are continually renegotiated by the various social players who, in different capacities, contribute to their modes of existence) in which the distinction - only seemingly obvious and fully justified - between places and the languages that talk about them fall to the wayside. As emphasized by Gianfranco Marrone (2013: 30), this involves recognizing that

what is typical for any cultural entity applies even more so to the city: the discourse it holds and the discourse about it are the same thing; they rely on and mutually implicate each other. If a city is first of all the memory that is stratified on it in culture, it seems evident that its identity is the final result - albeit one that is constantly being transformed - of everything it says with its own media (geographical, spatial, urbanistic, architectural), as well as everything that is said about it using every possible language (literature, painting, photography, cinema, etc.), including proxemics, idiosyncratic narrations and the value references of those who live in it, cross it and use it.

From the semiologist's perspective the starting point for an analysis of urban spaces first of all involves emphasizing that it is impossible to situate the city outside a reflection about signification, given that the sense of any city is constituted by and manifested on a dual movement that necessarily revolves around the concept of language, and it ultimately becomes profoundly rooted. 
In fact, on the one hand cities are the object of a plurality of languages, textual forms and types of discussion. On the level of content, they are continually called into play by constant "talking", a polyphony that, by becoming stratified, allows places to acquire and manifest their own semiotic consistency, a depth in terms of signification that sets them in relation to other forms of spatiality, in relationships articulated in the form of analogies and differences, continuities and discontinuities. On the other hand, starting from the perspective of analysis regarding enunciation, cities can be viewed as "subjects" that can produce and feed a large number of discourses pertaining to separate genres that, in turn, are fully manifested in the form of a multiplicity of often syncretic languages. Investigating the cultural identity of the city, exploring its meaning, thus means recognizing first of all the interdependence of these two movements, the "spoken" city and the city understood as a subject that can produce and circulate discourses and texts.

It is important to note that recent studies on signification thoughts on the semiotic nature of urban spaces have increasingly been supplemented by two very topical research trends, dedicated respectively to analysing everyday life practices and media languages, thereby contributing to a very open debate that probes a general theory of meaning as well as the methodological instruments needed to "interrogate" increasingly differentiated bodies of text.[2] Therefore, it is no accident that the city has acquired an increasingly important role within sociosemiotics, understood as "semiotics of significations founded, shared and transformed in social interactions" (Pozzato 2012: 8).

Starting from these premises, and leaving the vast and complex debate on the peculiarities that distinguish the sociosemiotic approach in the human and social sciences in the background, I will attempt here to investigate the correlation between some of the sweeping transformations that have marked everyday life practices in city spaces and the circulation of conversational media (social networks), which are increasingly aimed at closing the gap between direct experiencing the sensible world and sharing its narrative rendering.

More specifically, I will attempt to take a sociosemiotic approach to certain phenomena of uniform representation of everyday living in urban spaces, a profound transformation that, from a narrative standpoint, proves to be correlated with the growing use of social networks.

In fact, on the scenario of digital media the centrality of the "common sense", of the sharing of experiences, practices and rituals, has never emerged as strongly as it has now, favoured by the keen competition among the various social networks that urge forms of competition increasingly based on the narration of everyday life. In particular, the integrated geolocation of the main social networks and the easy Internet access guaranteed by WiFi networks have together contributed to profoundly redrawing the boundaries between the direct experience of everyday urban living and the sharing of that experience. From the standpoint of sociosemiotic reflection centred on the concepts of the signification at play in everyday life practices, one of the most stimulating issues to explore must necessarily involve the sweeping transformations that have been fuelled by the pervasiveness of digital media, which promote a "natural" integration of:

- technological innovation;

- urban territories;

- social networks.

- the sphere of human sensibility. 


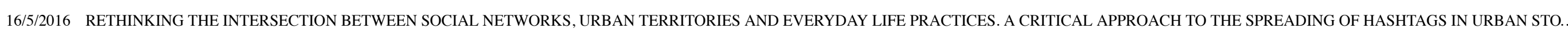

With social media, the correlation between direct experience and the urban spaces in which the various life forms and practices unfold is undergoing significant transformations. As several scholars have highlighted (e.g., Lovink 2012), managing one's profile, web reputation and, more generally, conversations with one's reference communities can look like a "collective obsession". For example, more and more often, before participants in a live event even take part actively, the object of the direct experience is named through a keyword (an official hashtag) in order to regulate conversations revolving around it and share them online.

One of the most significant aspects of regulating sensible experience that has emerged thanks to ever-smarter technology is the playful side of "ordinary" living, with particular reference to metropolitan scenarios. In the processes of regulating everyday life,[3] metropolises and the forms of life that unfold in them emerge as "playing fields" with variable boundaries, resources of potential signification processes whose nature is still uncertain but unquestionably of great interest. Advanced experiments in augmented reality such as Google Ingress and wearable computers like Google Glass bear witness to a playful reconfiguration process of the shared forms of experience that characterize everyday life in urban agglomerations. This increasingly pervasive technology - immediate and easily accessible, like the type that has long been available on ordinary smartphones - draws on the stratified processes of signification through which inhabitants experience a metropolis every day.

Taking up this perspective, the signification at play in metropolitan living thus lends itself to being examined by exploring some of the more striking forms of therenegotiation, regulation and sharing of the direct and indirect experience of places. This channelling of forms of everyday life is interpreted in the social media from a narrative approach, creating what is known as urban storytelling.

To contribute to thoughts about some of the transformations that characterize the interdependence between urban spatiality and social discourses, I will examine some of the most topical forms that the narrativization of everyday living has acquired in the context of social networks, examining three interrelated axes:

- media semiotics (in the light of the experiential turn,4] viewed as regulating and renegotiating devices that can activate unique forms of experience)

- urban semiotics (considering urban spaces not simply as a context in which the multiple phenomena of signification are inscribed and acquire meaningfulness, but as a semiotically dense and stratified form, a co-text in every sense of the word, equipped with its own consistency and its own language)

- the semiotics of everyday life (understood as one of the thresholds of contemporary semiotic research in which reflection on the systems and processes of signification is extended from texts and discourses to styles and life practices).

Taking up the critical reflection developed by Ruggero Eugeni (2010a: 17) towards the project - rather widespread on the composite panorama of media studies - aimed at underscoring naturalization of the experience and, by extension, of the media experience, this will thus involve emphasizing the critical vocation of the semiotic approach, the legitimacy of a method aimed first of all at "undermining the bases of an ideological project pursued by the media: affirming the imperceptibility of their activity".

In this sense, it will entail disputing the presumed naturalization of the media experience, debunking the innocence and transparency of the media apparatuses that regulate access to a vast array of experiential resources and, if anything, reasserting the projectual and planned nature that 

characterizes the increasingly closer relationship linking social networks, everyday life and urban spaces.

In keeping with critical reflection on the common sense that represents one of the orientations of semiotic research into the mythologies of everyday living (moving from the pioneering work that was introduced by Roland Barthes and that, even today, is at the centre of a debate extending outside the boundaries of semiotics), I will attempt to offer a sociosemiotic perspective for the analysis of certain discourses that hinge on life practices in urban spaces. This will focus on the proliferation of signs that are seemingly obvious and "transparent" but are actually filled with repercussions in the effects of meaning: what we refer to as hashtags.

\section{The proliferation of hashtags: keywords of common sense}

The word hashtag is a neologism, an expression combining the words "hash" (short for hash mark) and "tag". The hashtag is a type of tag[5] used by a growing number of social networks to create labels that can help circumscribe the topic of a conversation.

Hashtags are composed of concatenated words or combinations of words that, by convention, are preceded by the \# symbol (hash mark). On an international scale, this instrument for the creation, sharing and regulation of conversations centred on specific contents spread rapidly following its use in the protests that broke out in Iran during the 2009 presidential elections. Twitter, which originally did not feature a service to group its users' messages (tweets), adopted the hashtag as an easy-to-use tool to index content. In 2009 Twitter began to extend hashtag hyperlinks to all recent messages with the same keyword, making it so much easier to find and share content that it fostered the practice of "live tweeting", meaning real-time comments on an event by subjects who experienced it either directly or indirectly by participating in the streams composing the conversations.

What makes analysis of this form of tagging fully pertinent to sociosemiotic reflection on the effects of meaning that emerge from the intersection of everyday life, urban spaces and media apparatuses is not merely the growing circulation of hashtags - nothing short of a boom - but the emergence of a series of gradually more codified practices that define their use by a multitude of subjects of enunciation encouraged by social networks to share and add to discourses about their direct or mediated participation in urban life.

When we observe how the use of hashtags has changed in only a few years, what clearly emerges is that this instrument goes far beyond the labelling of topics by the subjects participating in a conversation. In fact, the decision to use a given hashtag is part of a sociosemiotic logic that is far more sweeping in scope and that, with specific reference to communicative exchanges involving users' experiences, consists of a widespread regulation of the sensible experience.

Indeed, attributing a hashtag to a place or event defined by precise spatio-temporal coordinates is never a neutral operation - mere naming - but instead involves an attempt to circumscribe, channel and orient the experience as it unfolds to ensure it is shared as much as possible.

Therefore, hashtags should not be viewed as innocuous "captions" but, rather, as instructions for the use of urban spaces, keywords that circumscribe and increasingly orient a series of conversations on the meaning of places and practices for their consumption, involving a variety of different subjects. Consequently, the regulatory function of these signs - so widespread that they look normal, obvious and "natural" - must be contextualized within a metacommunicative logic. 


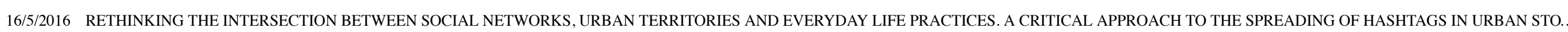
Significantly, the role played by hashtags in fuelling the process of regulating everyday life is clearly manifested by their massively growing use to encourage the sharing of digital photographs. In the process of the profound transformation of the ways of representing everyday living in urban spaces, the role of images, and specifically of digital photographs, has proven to be decisive. This clearly emerges if we consider the very widespread use of Instagram, the most famous free application allowing users to take pictures with a mobile device, apply an array of predefined filters and share the result on one's social platform as well as a variety of other networks.[6]

The use of sophisticated and portable media devices is obviously encouraged by the narrativity inherent in the conduct of everyday actions. More and more often, in fact, the level of the content acquired by the forms of textuality produced by media devices that are increasingly "incorporated" into individual actions is composed of a series of episodes from one's personal life, made accessible starting with the amply codified operations of selecting, posting and sharing everyday life practices.

In fact, the main characteristics of this type of application, which combines the functions of digital photo touch-ups and the sharing of content typical of the services of social networks, involve:

- the plastic level of the image, particularly the dimensions of the important crop function (the user is required to cut the initial image to make it fit into a square format that clearly alludes to the measurements of the famous Polaroid shots)

- colours, saturation and sharpness (parameters that can be modified simply, using a limited number of filters that make it possible to reproduce a declaredly vintage photographic aesthetic very easily)

- the option to write short comments, use tags to make the photograph easy to find and, lastly, activate geolocation to visualize the place where the picture was taken.

The growing success of this application, the circulation of the neologism "Instagramming" (now commonly used to refer to the use of filters for photo touch-ups) and the emergence of a series of increasingly codified and shared practices in the choice of hashtags to associate with pictures testify to a gradually more evident process of channelling the media experience that is powerfully documented in everyday use and that contributes to augmenting the semiotics of the common sense. In other words, a fully regulated representation of sensible activity that permeates the traces of ordinary living. In this regard, if we observe many of the images tweaked using Instagram filters and categorized based on specific hashtag choices, at least two other significant aspects emerge for sociosemiotic reflection.

On the one hand, we find the collective process of the segmentation of everyday life in the form of a series of powerfully codified narrative programmes, a "cropping" of the common sense that helps document the everyday story revolving around well-defined traces of the experience, named unmistakably thanks to hashtags (\#breakfast, \#work, \#school, \#shopping, \#dinner). With the flow of everyday life, we thus identify, select, name and share a set of common experiential resources that can potentially add to the level of the content of the photographic image and, by extension, the set of conversations it has triggered.

On the other hand, recourse to a common experiential design (Eugeni 2010),[7] facilitated by applications characterized by interfaces that are more and more user friendly, plays a decisive role in tracing the images of ordinary life to a series of preordained and thus common aesthetic forms. The 


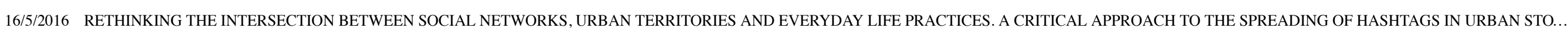
same colour balance, the same lighting effects, the same blurring are used extensively by growing numbers of users to tweak photos depicting very distinct everyday practices. One of the most striking consequences of this widespread and rather wholesale use of standardized visual effects is the overproduction and sharing of pictures that refer to an often standardized representation of the forms of contemporary life.

More precisely, Instagram interface fosters the overproduction and sharing of images that frequently contribute to the production and circulation of a codified representation of living in urban spaces. In this regard, Hochman and Manovich (2013: 12) recently affirmed that Instagram, intended not primarily as a medium but as a software artefact, superimposes its strong "message" (or "interface signature") on its users, shaping what and how they communicate.

Taking up this reflection, we can identify the sociosemiotic dynamic underpinning the success of applications such as Instagram in the importance that sharing daily experience acquires for users with respect to the signification processes involved in the photographic image. In other words, the use of photography is aimed not so much atshowing something but at showing oneself (and thus making oneself recognized), which responds to a series of shared practices that regulate the circulation of conversations.

As already mentioned, an even more striking sign of this marked tendency towards the aesthetization of ordinary life emerges if we examine the relationship established between the contents of conversations and hashtags. The interdependence between hashtags and photographs never consists of a simple complementary function, and instead we can observe that these keywords go beyond the meaning of the picture itself. The hashtags referring to the forms and practices of life in urban spaces should not be understood as labels whose function ends with one of the many discourses on cities. If anything, their proliferation contributes to redefining the very sense of the places of contemporary life, and more precisely that effect of overall sense through which a city acquires semiotic significance.

In this regard, we should mention the considerations recently advanced by Gianfranco Marrone on how semiotics intervenes in redefining the nature of the city, identifying its foundation ahead of the structural characteristics of the inhabited space, precisely in the dynamic and continually renegotiable processes of the production of signification.

The city is a city-effect expressed in some cases through an empirical city in its entirety and in others through a small part of it, and in yet others through any type of communicative support or expressive material [...] Even before its internal configuration, in its structure a city is constituted starting with its boundaries, thanks to the fundamental semiotic act for which the production of a difference is the construction of meaning (Marrone 2013: 11).

If the objective of semiotics is to identify - beneath the surface of urban spaces - the depth and complexity of a true language (seemingly hidden and the object of various and often unknowing uses by the very subjects who practice it), it is fully legitimate to recognize that what underlies the proliferation of hashtags dedicated to cities is the presence of a social discourse that inevitably impacts the cultural identity of urban places. 


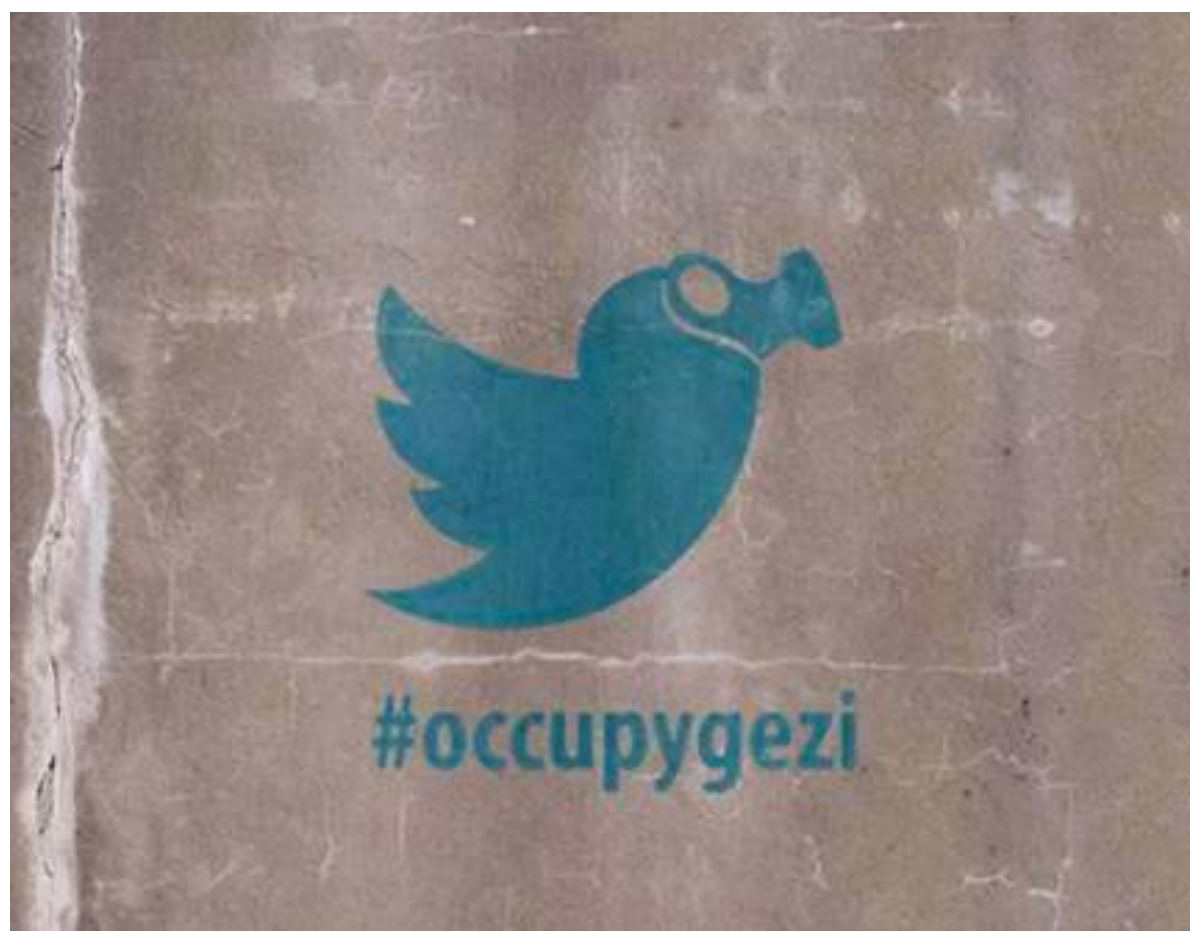

Fig. 1

In fact, hashtags contribute to the construction/renegotiation of the city-effect, establishing new boundaries around an "object" that is already semiotically complex, selecting and clearly expressing - often based on ordinary life actions - a series of isotopies, narrative paths and figurative elements, and ultimately renegotiating the limits that separate the concrete city from the discourses that talk about it and that it produces. This seems evident from an ethnosemiotic standpoint if we observe the multiplication of hashtags in the tangible places of consumption, culture and protest. 


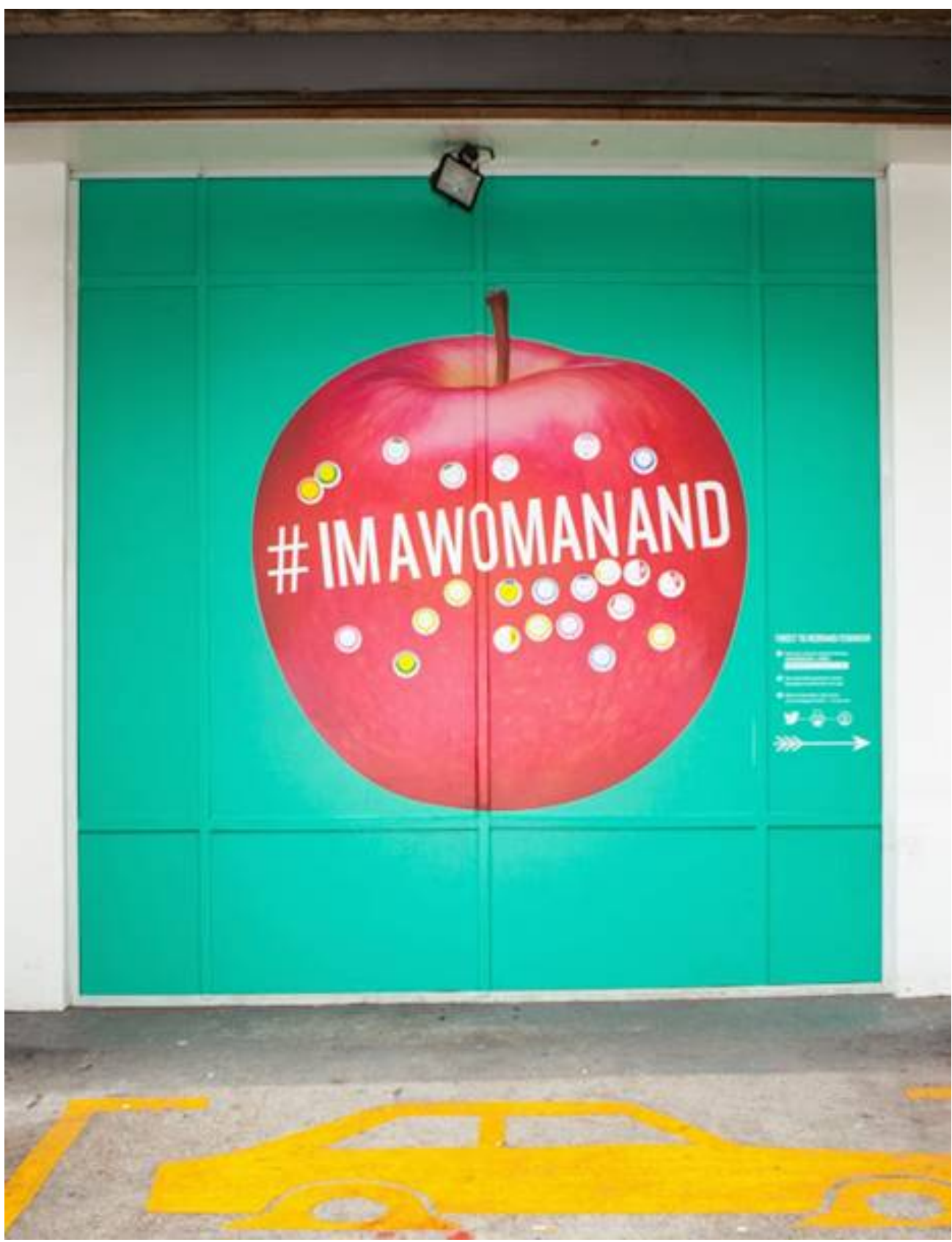

Fig. 2

Consequently, the spontaneous phenomenon of "live tweeting" generated during local events, be they planned or impromptu and often ahead of http://www.iass-ais.org/proceedings2014/view_lesson.php?id=99 

coverage by traditional media, can be considered a contribution - sometimes decisive - to the intersubjective negotiation of the sense of what is happening in urban spaces.

The conventional representation of daily life in urban spaces is thus translated into a series of behavioural and interpretational instructions for the actual space and the intersubjective relationships manifested in it. It is from this perspective that the function of these keywords - by no means obvious or innocent - emerges.

\section{Urban storytelling: an expanded and regulated metadiscourse}

By introducing the significance of an expanded but also regulated metadiscourse, hashtags support the process of sharing a common experience that is interpreted on a narrative level and in which we find a scopic dimension (related to the circulation of views that regulate access to an object of everyday experience), a cognitive dimension(related to the circulation of knowledge) and, obviously, a dimension that involves the subjects' passionate, emotional sphere. From the perspective of semiotics of the digital media, this form of storytelling can be defined as expanded, because:

- in terms of enunciation it is open to the contribution of a variable number of subjects with different skills and interests;

- it does not envisage linear development;

· it is fuelled by multiple languages;

- it extends across the various social platforms;

- it does not have a predefined time limit.

At the same time, it seems strongly regulated, given that the circulation of images and, more generally, of discourses on the various shared practices is based on acceptance of a set of habits involving not only the choice of situations to photograph, the positioning of the media device, the composition of the framing or the filters to use, but most importantly the choice of hashtags that will ensure their visibility.[8]

Another striking signal of the standardized representation process of everyday life is the fact that, particularly with regard to more active users, the popularity of the various hashtags is what orients the choice of situations to photograph and share in conversations.[9]

In this regard, a widely documented practice consists of multiplying the hashtags associated with a photograph in order to make it shared more widely, drawing on a series of very distinct categories that impact the city-effect on different levels (thematic, narrative, figurative).

In particular, it seems increasingly apparent that the semiotic logic underlying the function of stereotypes orients the choices of a growing number of subjects, guaranteeing access to a store of reconstituted meaning. Aside from hashtags that perform a referential function, indicating the place and the time of year, what proliferate are keywords that refer to a number of clichés, evoking arguments, situations, practices, passions, objects and figures strongly rooted in the shared imagination. This can be observed in the terms most frequently associated with photographs dedicated to a cult city such 

as Paris:

\#cestmonparis, \#walkinginparis, \#parisianlocal, \#urbanromantic, \#parisian, \#parisfashionweek, \#parisbynight, \#parisjetaime, \#baguettes, \#parissaintgermain, \#parisamour, \#parisstreetart, \#parislife, \#parisatnight, \#cityoflight, \#villelumiere, \#parismaville.

In this metadiscourse centred on the common sense, the strength of a hashtag often proves to be very ephemeral and inevitably temporary, tied to the subjects' ability to generate engagement with the communities of followers and contribute to conversations.

It is particularly significant that the process of the constant updating of keywords also draws on pre-existing texts and discursive genres, fitting into an ecological relationship within the contents of a culture, a fully fledged semiotic ecology[10] characterized by marked internal dynamism, as can be observed in particular by examining the titles of films associated with the symbolic places of many cities.

To return to the example of Paris, an iconic example is unquestionably represented by the string of hashtags such as \#amelie \#ameliepoulain, \#cafedesdeuxmoulins and \#maisoncollignon, which do not consist of a mere sequence of labels naming the most representative places in Jean-Pierre Jeunet's famous film from 2001 and then photographed by Instagram users. This corroborates the correlation between access to the indirect world of the filmic discourse and the direct experience of the urban place in which it was set, impacting the sense of the photographic image and helping to resemanticize the city space and the everyday life practices conducted there.

The function of hashtags is thus not merely about anchoring the content of the photographic text or explaining the referential function of the image through which the user testifies in social networks to the fact that he or she is present at a popular place. The distinctive role of these keywords is instead to renegotiate the sense of an everyday life experience, while also increasing the targeted circulation of his or her story as a function of the semiotic concepts of interdiscursivity and intertextuality. In fact, the use of hashtags that conventionally refer to a specific film encourages "controlled" circulation of the photograph, allowing all interested users to access the archive of pictures marked with the same keywords and potentially help expand it.

The choice of these keywords and their combination, in the form of lists with a variable extension, thus inscribe a metadiscourse (that can naturally refer to an array of texts and media genres) within the story of personal experience, contributing to the continuous renegotiation of the distance separating direct experience from media experience. In other words, this increases the progressive regulation[11] of discourses revolving around life in urban spaces.

If we again expand our view of the use of hashtags not only on Instagram but on all the main social platforms, then from the standpoint of sociosemiotics, involved in analysing the reflexivity of the social sphere or, in other words, in studying the different modes through which "the social community gives itself in spectacle to itself and thus endows itself with the rules necessary for its own game (Landowski 1989: 13)", we cannot help but note that the proliferation of these keywords is underpinned by the progressive emergence of an open yet strongly regulated repertory of discourses that hinge on the common sense of living in urban spaces.

Overcoming the ingenuous idea of ascribing hashtags with a purely instrumental function in defining the topic of a message thus means recognizing the relevance of the effects of sense that these "labels" are progressively determining by regulating the daily use of social platforms. Analysis of the 
16/5/2016 RETHINKING THE INTERSECTION BETWEEN SOCIAL NETWORKS, URBAN TERRITORIES AND EVERYDAY LIFE PRACTICES. A CRITICAL APPROACH TO THE SPREADING OF HASHTAGS IN URBAN STO... relationship between these keywords and the textual and discursive forms to which they refer can help highlight the increasingly stratified yet also regulated nature of the processes of signification that emerge in the interaction of urban spaces, everyday life practices and conversational media.

The stakes for a critical reflection on the mythologies of contemporary life are quite high, as testified by the emerging and manifest signals of the irruption of stereotypes in the formation and circulation of the keywords of the common sense.

\section{Bibliography}

BARTHES, Roland. 1957. Mythologies. Paris: Seuil.

COSENZA, Giovanna. 2014. Introduzione alla semiotica dei nuovi media. Rome-Bari: Laterza.

DE OLIVEIRA, Ana Claudia (eds.). 2013. As Interações Sensíveis - Ensaios de Sociossemiótica a Partir da Obra de Eric Landowski. São Paulo: Estação das Letras e Cores.

EUGENI, Ruggero. 2010a. Semiotica dei media. Le forme dell'esperienza. Rome: Carocci.

EUGENI, Ruggero. 2010b. Nikeplatz. The Urban Space as a New Medium. Paper presented at NECS Conference, Istanbul, Turkey, June $24-27$.

FABBRI, Paolo. 2001. La svolta semiotica. Rome-Bari: Laterza.

FINOCCHI, Riccardo \& Daniele GUASTINI (eds.). 2011. Parole chiave della nuova estetica. Rome: Carocci.

FONTANILLE, Jacques. 2008. Pratiques sémiotiques. Paris: Presses Universitaires de France.

FONTANILLE, Jacques. 2004. Textes, objets, situations et formes de vie. Les niveaux de pertinence de la semiotique des cultures. E/C - Rivista online dell' Associazione Italiana di Studi Semiotici. http://www.ec-aiss.it/index_d.php?recordID=123 (on line publication 28 May 2004 ).

GREIMAS, Algirdas Julien 1976. Sémiotique et sciences sociales. Paris: Seuil.

HOCHMAN, Nadav \& Lev MANOVICH. 2013. Zooming into an Instagram City: Reading the local through social media. First Monday, 6/1/2013.

LANDOWSKI, Eric. 1989. La société réfléchie. Paris: Seuil.

LOTMAN, Yuri M. 1985. La semiosfera. L'asimmetria e il dialogo nelle strutture pensanti. Venice: Marsilio.

LOVINK, Geert. 2012. Networks without a cause: A Critique of Social Media. Cambridge: Polity Press.

MARRONE, Gianfranco, Nicola DUSI \& Giorgio LO FEUDO (eds.). 2007. Narrazione ed esperienza. Intorno a una semiotica della vita quotidiana. 


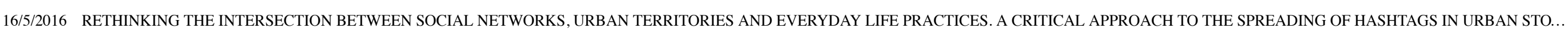
Rome: Meltemi.

MARRONE, Gianfranco \& Isabella PEZZINI (eds.). 2008. Linguaggi della città. Senso e metropoli II. Modelli e proposte di analisi. Rome: Meltemi. MARRONE, Gianfranco \& Isabella PEZZINI (eds.). 2006. Senso e metropoli. Per una semiotica posturbana. Rome: Meltemi.

MARRONE, Gianfranco. 2013. Figure di città. Spazi urbani e discorsi sociali. Milan-Udine: Mimesis.

MARSCIANI, Francesco. 2007. Tracciati di etnosemiotica. Milan: FrancoAngeli.

MONTANI, Pietro. 2007. Bioestetica. Senso comune, tecnica e arte nell'età della globalizzazione. Rome: Carocci.

MONTANI, Pietro. 2010. L'immaginazione intermediale. Perlustrare, rifigurare, testimoniare il mondo visibile. Rome-Bari: Laterza.

PEVERINI, Paolo. 2011. Fotografia e urban storytelling. Forme del mashup nel web 2.0, in Maria Claudia Brucculeri, Dario Mangano and Isabella Ventura (eds.), La fotografia. Oggetto teorico e pratica sociale. Laboratori, 73-77. Rome: Edizioni Nuova Cultura.

PEVERINI, Paolo. 2012. I media. Strumenti di analisi semiotica. Rome: Carocci.

PEVERINI, Paolo. 2012. Parole chiave e mitoidi d'oggi. Riflessioni semiotiche sulla nuova estetica del senso commune. E/C - Rivista on-line dell'Associazione Italiana di Studi Semiotici. http://www.ec-aiss.it/index_d.php?recordID=651 (on line publication 29 October 2012).

PEVERINI, Paolo. 2011. Fotografia e urban storytelling. Forme del mashup nel web 2.0, in Maria Claudia Brucculeri, Dario Mangano and Isabella Ventura (eds.), La fotografia. Oggetto teorico e pratica sociale. Laboratori, 73-77. Rome: Edizioni Nuova Cultura.

PEZZINI, Isabella. 2004. Un approccio semiotico allo studio dello spazio nella città, in Franco Martinelli (ed.), Città e Scienze umane, $257-264$. Naples: Liguori, 2004.

PEZZINI, Isabella. 2008. Immagini quotidiane. Sociosemiotica visuale. Rome-Bari: Laterza.

POZZATO, Maria Pia. 2012. Foto di matrimonio e altri saggi. Milan: Bompiani.

VOLLI, Ugo. 2013. Quale ecologia della comunicazione? In Claudio Bisoni, Veronica Innocenti (eds.), Media mutations. Gli ecosistemi narrativi nello scenario mediale contemporaneo. Spazi, modelli, usi sociali, 27-34. Modena: Mucchi Editore.

[1] We need merely recall the considerations advanced by Yuri Lotman on the semiotic complexity of the urban space (1985, 232): "The city as a complex semiotic mechanism, a generator of culture, can carry out this function only because it is presented as a container of texts and codes that formed in different ways, are heterogeneous, pertain to different levels and make use of different languages". 


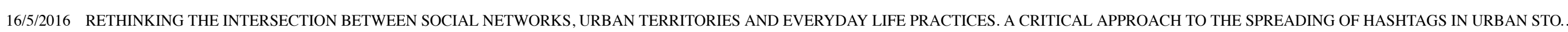
[2] In particular, as clarified by Maria Pia Pozzato (2012, 7), in sociosemiotic analysis "it is extremely difficult to subject every element to orderly and exhaustive analysis as was done in those happy times when we were dealing with texts in the strict sense of the word, and mainly literary or ethnoliterary ones, certainly more reassuring in authorizing the procedures of closing and making their components consistent. The sensation was also that, from an analysis of these texts, it was easy to extrapolate a series of significant basic elements, a grammar of the human imagination destined to illuminate any other text."

[3] Where, as Pietro Montani (2010, p. xvii) notes, aesthetics is not considered "a way of philosophizing about art, but a critical reflection the object of which is the entire realm of sensibility (aisthesis)."

[4] On this, see the thoughts of Ruggero Eugeni (2010) regarding the experiential watershed in media studies.

[5] The scholar who investigated the collaborative nature of hashtags is Derrick De Kerckhove, who conceives of this type of label as a key element of what he calls "connected intelligence", intuitive instruments that allow an enormous number of subjects to manage communicative exchanges. According to De Kerckhove, the very nature of the Internet, the essential principle underlying its operation, is embodied by the tagging process, encouraging the practices of creation and sharing of contents that are potentially uninterrupted, meaning that they are "always on".

[6] Among these, the most popular are Twitter, Facebook, Foursquare and Tumblr.

[7] As maintained by Eugeni (2010a, 16-17), the media experience "is artificial, pre-constituted and serial; it responds to an experiential design and takes on the responsibility of making this project operative within ordinary experience. This unique characteristic also means that it constitutes a particularly complex form of experiences, as it overlaps a directly perceived world with one that is perceived indirectly and it introduces the irreducible depth of discourse".

[8] Examples of the many popular hashtags include \#wakeup, used to narrate what happens after getting out of bed, \#foodporn, \#instafood and \#yummy that, by convention, are associated with photos that enhance the details of dishes thought to look especially appealing. With reference to urban spaces, particularly popular hashtags include \#architexture, \#streetphotography, \#urbanart, \#streetart, \#wallporn, \#architecturelover and \#instagraffiti.

[9] In this sense, the numerous websites devoted to the use of Instagram are particularly significant. In these, users can find suggestions for the best hashtags to associate with pictures and a constantly changing list of keywords.

[10] On this issue of semiotic ecology, Volli $(2013,34)$ maintains that "in reality, semiospheres and ecologies are theoretical constructs and the only empirical subjects are messages and speakers/readers. The issue of semiotic ecology must be referred to the action, interest and pleasure of these figures. Nevertheless, just as semiospheres have to do with mass phenomena rather than individual communicative actions, so do their users, speakers or readers, who are not individuals but social groups. Grammars, skills and languages are not mental and essentially individual elements, but social ones.And it is on a social level that the phenomena of sense typical of semiotic ecology come into play."

[11] In this regard, it is unquestionably important to emphasize that the very logic of how social networks such as Instagram - but also Facebook, 
16/5/2016 RETHINKING THE INTERSECTION BETWEEN SOCIAL NETWORKS, URBAN TERRITORIES AND EVERYDAY LIFE PRACTICES. A CRITICAL APPROACH TO THE SPREADING OF HASHTAGS IN URBAN STO... Twitter and Pinterest - work is what elicits users to adopt a series of practices for using hashtags aimed at improving the visibility and potential engagement of messages.

ISSN 2414-6862 Proceedings of the world congress of the IASS/AIS

(C) IASS Publications \& NBU Publishing House 2016; 21, Montevideo str., 1618 Sofia, Bulgaria 